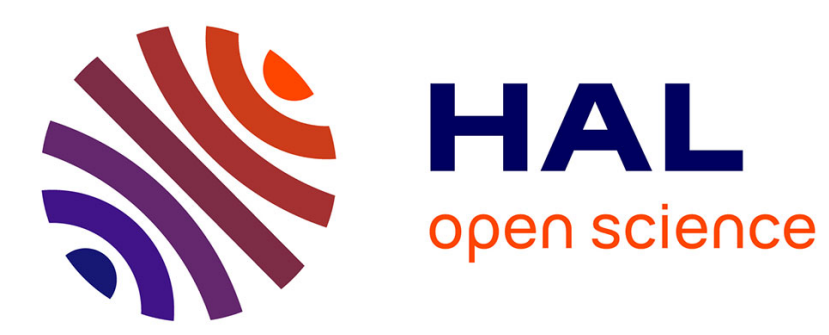

\title{
LOCALIZATION AND ULTIMATE TENSILE STRENGTH OF FIBER-REINFORCED CERAMIC-MATRIX COMPOSITES
}

François Hild, Alain Burr

\section{To cite this version:}

François Hild, Alain Burr. LOCALIZATION AND ULTIMATE TENSILE STRENGTH OF FIBERREINFORCED CERAMIC-MATRIX COMPOSITES. Mechanics Research Communications, 1994, 21 (4), pp.297-302. 10.1016/0093-6413(94)90051-5 . hal-01636217

\section{HAL Id: hal-01636217 https://hal.science/hal-01636217}

Submitted on 31 Oct 2019

HAL is a multi-disciplinary open access archive for the deposit and dissemination of scientific research documents, whether they are published or not. The documents may come from teaching and research institutions in France or abroad, or from public or private research centers.
L'archive ouverte pluridisciplinaire HAL, est destinée au dépôt et à la diffusion de documents scientifiques de niveau recherche, publiés ou non, émanant des établissements d'enseignement et de recherche français ou étrangers, des laboratoires publics ou privés. 


\section{LOCALIZATION AND ULTIMATE TENSILE STRENGTH OF FIBER-REINFORCED CERAMIC-MATRIX COMPOSITES}

François Hild and Alain Burr

Laboratoire de Mécanique et Technologie,

E.N.S. de Cachan / C.N.R.S. URA 860 / Université Paris 6

61 avenue du Président Wilson, F-94235 Cachan Cedex, France.

\section{Introduction}

The stress-strain behavior of ceramic-matrix composites (CMCs) is often non-linear. The loading of such composites results in two independent damage mechanisms: fiber failure and matrix cracking. Furthermore, the fibers are supposed to be subject to global load sharing, whereby the load transmitted from each failed fiber is shared equally among the intact fibers. Some aspects of the associated fiber failure stochastics have already been addressed [1-4]. The results usually overestimate the ultimate tensile strength observed experimentally. Moreover, the nonlinearity is overestimated as well [5]. In this paper, the problem is analyzed in the light of results related to strain localization [6]: by strain localization we mean the localization of fiber breakage and fiber pull-out into one plane of matrix crack. 


\section{Expression of the Ultimate Tensile Strength}

A composite with a saturation density of matrix cracks is considered, spacing $L_{m}$, within a unit cell of length $L_{R}$. The length $L_{R}$ is the recovery length and refers to the longest fiber $\left(L_{R} / 2\right)$ that can be pulled out and cause a reduction in the load carrying capacity. The recovery length is thus related to the reference tensile stress $T$ in unbroken fibers by

$$
\mathrm{L}_{\mathrm{R}}=\frac{\mathrm{RT}}{\mathrm{t}}
$$

where $\tau$ is the interfacial shear resistance, and $R$ the fiber radius.

If the fibers exhibit a statistical variation of strength that obeys a two-parameter law, then the probability that a fiber would break anywhere within the recovery length $\mathrm{L}_{\mathrm{R}}$ at or below a reference stress $T$ can be written as

$$
P_{F}(T)=1-\exp \left\{-\left(\frac{T}{S_{c}}\right)^{m+1}\right\}
$$

with

$$
S_{c}^{m+1}=\frac{L_{0} S_{0}^{m} \tau}{R}
$$

where $S_{c}$ is the characteristic strength [7], $m$ the shape parameter, $S_{0}$ the stress scale parameter, and $\mathrm{L}_{0}$ a reference length.

The average tensile stress $\bar{\sigma}$ applied to the composite is related to the reference stress T by

$$
\bar{\sigma}(T)=f T\left\{1-P_{F}(T)\right\}+\bar{\sigma}_{F P}(T)=\bar{\sigma}_{U F}(T)+\bar{\sigma}_{F P}(T)
$$

where $\bar{\sigma}_{\mathrm{FP}}(\mathrm{T})$ denotes that component of the stress provided by failed fibers as they pull out from the matrix. It has been shown that $\bar{\sigma}_{\mathrm{FP}}(\mathrm{T})$ is an increasing function and then saturates [8]. A first approximation [1] is given by $\bar{\sigma}_{\mathrm{FP}}(\mathrm{T}) \approx \mathrm{f} \mathrm{T} \mathrm{P}_{\mathrm{F}}(\mathrm{T}) / 2$.

In Fig. 1, the contributions of the two mechanisms, viz. fiber breakage and fiber pull-out, are plotted when $m=4$. It is worth noting that the contribution of the unbroken fibers, $\bar{\sigma}_{\mathrm{UF}}(\mathrm{T})$, reaches a maximum value prior to reaching the ultimate point. This result shows that a softening 
mechanism on a microscale takes place prior to the softening mechanism on a macroscale. This decrease leads to a loss of uniqueness and localization on a microscale beyond that point.

Since $\bar{\sigma}_{U F}(T)$ decreases, there are two alternatives. The first one, referred to as homogeneous solution, corresponds to the case where fiber breakage continues to evolve uniformly in the whole specimen. This is only possible if the strains can be prescribed over the whole specimen. The second one, referred to as localized solution, consists in elastic unloading of the unbroken fibers in one part of the specimen, and further fiber breakage in the other part (whose size is on the order of the characteristic length $\delta_{\mathrm{c}}=\mathrm{RS}_{\mathrm{c}} / \tau$ ). This localized solution appears as soon as the overall strain cannot be controlled on a microscopic scale. Otherwise, the homogeneous solution is the only solution to this problem. Consequently Eqn. (3) after the localization point corresponds to the homogeneous solution, which usually cannot be reached.

The applied stress level corresponding to the onset of localization will be referred to as localization tensile strength, and will be denoted by $\bar{\sigma}_{\mathrm{LTS}}$. In most cases, this stress level corresponds to the ultimate tensile strength of a CMC. The aim of the remainder of this Section is to derive this stress level and to compare it with the ultimate tensile strength given by the homogeneous solution.

In fiber-reinforced composites, broken fibers cannot control the strains: only unbroken fibers within the recovery length control the strains. As soon as $\bar{\sigma}_{\mathrm{UF}}(\mathrm{T})$ reaches a maximum, the overall strains cannot be controlled on a microscale. Therefore, a localized solution appears when $\bar{\sigma}_{\mathrm{UF}}(\mathrm{T})$ achieves its maximum. The localization tensile strength of the composite is thus given by

$$
\bar{\sigma}_{\mathrm{LTS}}=\bar{\sigma}\left(S_{c}\left\{\frac{1}{m+1}\right\}^{1 /(m+1)}\right)=\bar{\sigma}\left(T_{L}\right)
$$

where $T_{L}$ is the value of the stress in the unbroken fibers when $\bar{\sigma}_{U F}(T)$ achieves its maximum. At localization, the tangent modulus at the onset of localization on a microscale is still positive

$$
\frac{\mathrm{d} \bar{\sigma}\left(\mathrm{T}_{\mathrm{L}}\right)}{\mathrm{d} \overline{\boldsymbol{E}}}=\frac{\mathrm{d} \bar{\sigma}_{\mathrm{FP}}\left(\mathrm{T}_{\mathrm{L}}\right)}{\mathrm{d} \overline{\boldsymbol{\varepsilon}}}>0
$$

By using the previous approximation of the pull-out stress, the localization tensile strength becomes 


$$
\bar{\sigma}_{\mathrm{LTS}} \approx \frac{\mathrm{fS}}{2}\left(\frac{1}{\mathrm{~m}+1}\right)^{1 /(\mathrm{m}+1)}\left\{1+\exp \left(-\frac{1}{\mathrm{~m}+1}\right)\right\}
$$

On the other hand, the ultimate tensile strength, corresponding to the response of the homogeneous solution, is given by

$$
\bar{\sigma}_{U T S}=\operatorname{Max}\{\vec{\sigma}(T) ; T \geq 0\}
$$

This equation cannot be solved analytically. A first order solution of the ultimate tensile strength is given by [1]

$$
\bar{\sigma}_{U T S}=f S_{c}\left\{\frac{2}{m+2}\right\}^{1 /(m+1)} \frac{m+2}{m+1}
$$

In Fig. 2, the ultimate tensile strength is compared with the localization tensile strength for different values of $\mathrm{m}$. It is worth noting that in terms of stress levels, the two strengths are very close. However, in terms of failure strains, and ductility, the two differ more significantly (Fig. 1). More importantly, as mentioned earlier, the tangent modulus is equal to zero when the ultimate tensile strength is reached whereas it is still positive when the localization on a microscale sets in. In the following, the tensile strength derived from Eqn. (8) is compared with the localization tensile strength given by Eqn. (6) in the case of carbon-matrix composites.

\section{Comparison with Experiment}

Experiments performed on two carbon-matrix composites (material $A$ and $C$ ) reinforced by $\mathrm{SiC}$ (Nicalon) fibers [9] are summarized in Table 1: $\mathrm{L}_{0}=25 \mathrm{~mm}, \mathrm{R}=6.5 \mu \mathrm{m}$. The predictions agree well with experiments (Table 2). In particular, in these experiments, the stressstrain response does not show that the tangent modulus at the ultimate is vanishing. This is consistent with Eqn. (5): the onset of localization on a microscale sets in when the tangent modulus is still positive. This last result has been observed in various fiber-reinforced composites [5]. 
EXPERIMENTAL RESULTS

\begin{tabular}{|l|l|l|l|l|l|}
\hline Material & $\mathrm{f}$ & $\mathrm{S}_{0}(\mathrm{MPa})$ & $\mathrm{m}$ & $\tau(\mathrm{MPa})$ & $\bar{\sigma}_{\mathrm{TS}}(\mathrm{MPa})$ \\
\hline $\mathrm{A}$ & 0.2 & 1165 & 4.5 & 10 & 290 \\
\hline $\mathrm{C}$ & 0.2 & 1140 & 4.5 & 14 & 345 \\
\hline
\end{tabular}

Table 1: Experimental results for carbon-matrix composites.

\section{PREDICTIONS}

\begin{tabular}{|l|l|l|}
\hline Material & $\bar{\sigma}_{\text {LTS }}(\mathrm{MPa})$ & $\bar{\sigma}_{\text {UTS }}(\mathrm{MPa})$ \\
\hline$A$ & 295 & 310 \\
\hline$C$ & 310 & 325 \\
\hline
\end{tabular}

Table 2: Predictions of the tensile strength for carbon-matrix composites.

\section{Acknowledgments}

The authors are indebted to Prof. Frederick A. Leckie for valuable discussions. This work has been supported by the Defense Advanced Research Project Agency through the University Research Initiative under Office of Naval Research Contract No. N-00014-92-J-1808.

\section{References}

1. W.A. Curtin, J. Am. Ceram. Soc., 74 (11), 2837-2845 (1991).

2. S.L. Phoenix and R. Raj, Acta Metall. Mater., 40 (11), 2813-2828 (1992).

3. W.A. Curtin, J. Mech. Phys. Solids, 41 (1), 35-53 (1993).

4. S.L. Phoenix, Comp. Sci. Tech., 48, 65-80 (1993).

S. U.R.I., Winter Study Group, University of California, Santa Barbara (U.S.A.) (1994).

6. F. Hild et al., Int. J. Solids Struct., 29 (24), 3221-3238 (1992).

7. R.B. Henstenburg and S.L. Phoenix, Polym, Comp., 10 (5), 389-406 (1989).

8. W.A. Curtin, J. Mat. Sci., 26, 5239-5253 (1991).

9. F.E. Heredia et al., J. Am. Ceram. Soc., 75 (11), 3017-3025 (1992). 

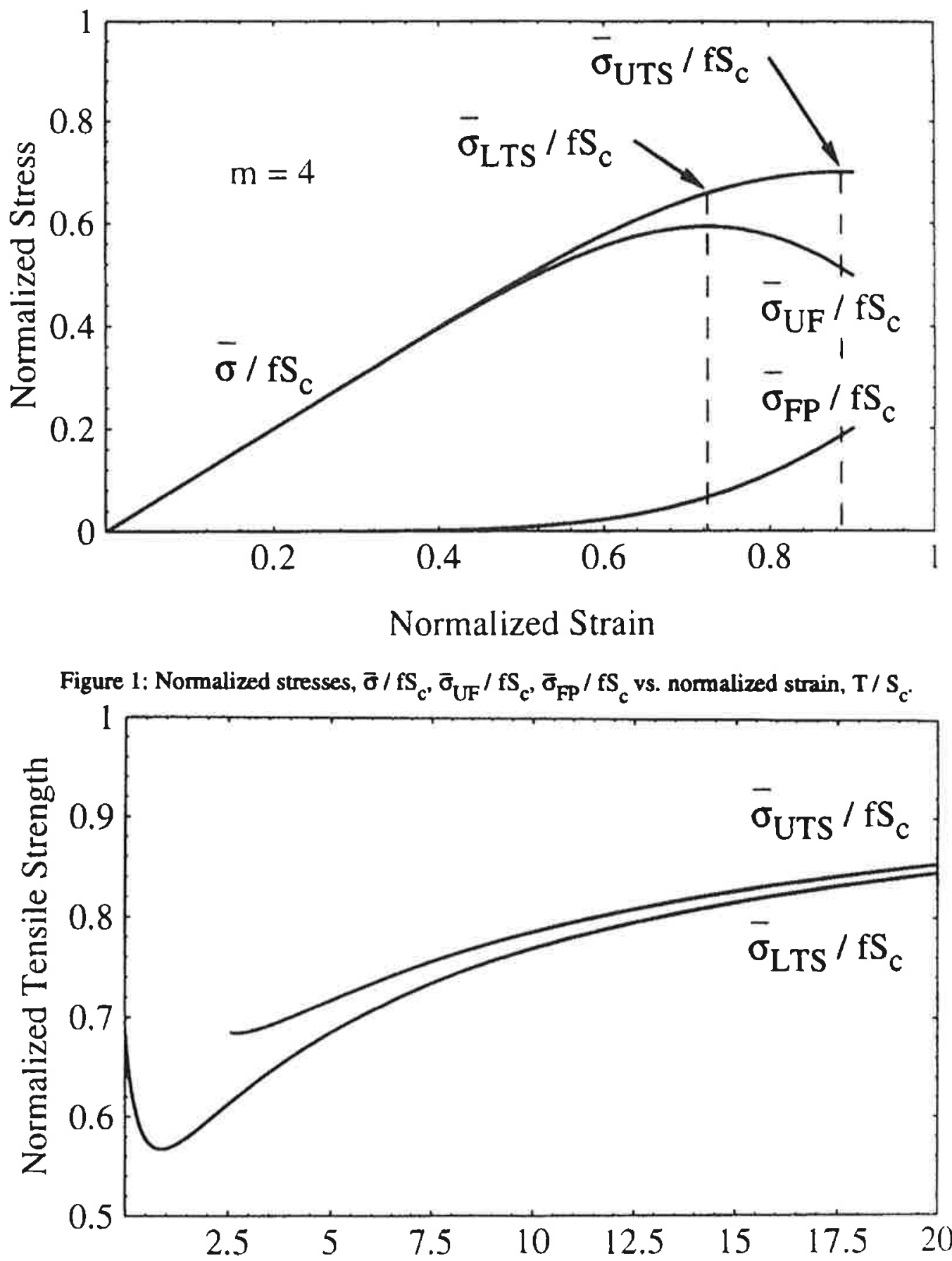

Weibull Modulus

Figure 2: Normalized tensile strengths, $\bar{\sigma}_{\mathrm{LTS}} / \mathrm{fS}_{\mathrm{c}^{\prime}}, \bar{\sigma}_{\mathrm{UTS}} / \mathrm{fS}_{\mathrm{c}}$ vs. Weibull parameter, $\mathrm{m}$. 